\title{
Chilean University Students' Call for Participation and Engagement in What Matters to Them: Is It Possible to Achieve a Shared Decision Making Process in Education Policy?
}

\author{
Paulina Bravo ${ }^{1}$, Baltica Cabieses ${ }^{2}$ \\ ${ }^{1}$ School of Nursing, Pontificia Universidad Catolica de Chile, Santiago, Chile \\ ${ }^{2}$ Faculty of Medicine, Universidad del Desarrollo Chile, Santiago, Chile \\ Email: bravop17@gmail.com
}

Received August 30 $0^{\text {th }}$, 2012; revised September 30 ${ }^{\text {th }}$, 2012; accepted October $12^{\text {th }}, 2012$

\begin{abstract}
Chile is facing one of its major intellectual revolutions in the last century: organised high school, college and university students have led the most salient educational reform since the one that took place during the dictatorship period. This phenomenon is a pacific revolution based on the power of sound, evidence-based, clear and robust ideas. The purpose of this short essay is to reflect some ideas on the conceptualization of a shared decision making (SDM) process and how they could be transferred to the current students' educational revolution in Chile. It provides a reflection on how SDM might concretely contribute to this educational reform and on what future steps could be taken to truly achieve a "participatory" democracy in Chile. According to the authors, this debate illustrates the extent to which the level of participation must rely not on particular individuals but on the establishment of a partnership between parties.
\end{abstract}

Keywords: Higher Education; Revolution; Democracy; Chile; Shared Decision Making Process

\section{Introduction}

\section{The Current Students’ Pacific Revolutionary Movement in Chile, "Nothing about US without US"}

Chile is facing one of its major intellectual revolutions in the last century: organized higher education students have led the most salient educational reform since the one that took place during the dictatorship period. As reported by different journalists all over the world, hundreds of thousands of high-school and university students have refused to go to lessons since early June 2011, calling for better and more affordable education and an end to a two-tier system that creates a few wealthy, elite colleges amid many under-funded public ones.

This phenomenon is a pacific revolution based on the power of sound, evidence-based, clear and robust ideas. It is also based on profound and well-known social inequalities in Chile. As Commander Camila Vallejo said in an interview outside the presidential palace “We don't want violence... our fight is to recover the right to education, on that we have been emphatic and clear" (Franklin, 2011). What has been so convincing of this manifestation, not only to politicians but the entire civil society in Chile is that this is a well-informed, thoughtful and pacific protest, challenging one of the greatest social inequities in Chile, opportunity to and quality of public education.

Education inequalities in Chile are significant and pervasive over time. In 2006, $7 \%$ of the total Chilean population reported no education at all, 35\% primary level only, 30\% secondary education and the rest higher education (Cabieses et al., 2010). The higher the educational level, the better health status and general wellbeing; the higher living standards; and the longer the life expectancy in the country. These patterns are maintained after adjusting by age, sex and ethnicity. For example, between
1998 and 2006, life expectancy at age 20 increased by 1.5 years, but this increase was not homogeneous by educational level. Life expectancy at age 20 for men without schooling increased by 0.8 years, while for the group with 13 or more years of education, the increase was 2.8 years (Chilean Ministry of Health, 2011). Education affects life opportunities, health and wellbeing from early life and it is usually maintained over generations. Poor people in Chile cannot afford adequate education since preschool onwards, and that affects other significant dimensions of their development through the life span. Those in wealthy families in turn, experience great opportunities and education from early in their lives, which supports their healthy development and the one of their future generations.

This revolution represents the existence of a well-informed and empowered civil society in Chile, possibly a partial consequence of the country's socioeconomic instability and democratic development in the past three decades. What is particularly interesting of this situation is the consistent claim of students to develop a real "participatory" democracy in Chile. They have been challenged several times in the past weeks to explain what they refer to exactly when they use this phrase, and they have systematically approached this debate in a quite convincing way. For them, Chile has not yet achieved true democracy, because there is no real participation of different parts of society in the decision making process of any policy or law in the country. They insist in a shared decision making (SDM) process from the very early stages of any social process, and define such participation in the broadest possible way. To them, every individual living in Chile should somehow have a clear voice to represent them in the Senate and any other institution of the Government.

The purpose of this short essay is to reflect some ideas on the conceptualization of a shared decision making process and how 
they could be transferred to the current students' revolution in Chile. The key questions this essay aims to answer are the following:

1) What is SDM, what are its components and stages?

2) How can the current knowledge on SDM contribute to the debate held by the Chilean Government and the students in the country?

3) In opinion of the authors, what future steps should be taken to contribute to achieve true "participatory" democracy in Chile?

\section{The Shared Decision Making Process (SDM), a Conceptual Overview}

SDM has been defined as a style of leadership (Kuhns and Chapman, 2006). It provides empowerment to all parties involved in a decision (Liontos, 1994) (North Central Regional Educational Laboratory). This style of leadership has been most studied in the healthcare context. With almost 30 years of history, researchers on SDM in health have stated that this is an approach which involves people in the process of making decisions, considering people's preferences, values and autonomy (Hårter et al., 2011). SDM in health has highlighted that the importance of involving people in the decision making process is based on trust, truthfulness and respect for people's choices (Niemira, 2009). It has been defined as an ethical imperative, because people have the right to participate in decisions that matters to them (Elwyn, 2010). SDM does not support paternalistic approach, where health providers are the "experts" and the only responsible for the decision making process. Neither it is restricted to an informed choice model, where sufficient information is provided to the patient but health professionals abandon the decision making process (Elwyn et al., 1999). SDM advocates for the involvement of people in their health-related decisions, as they become partners of the health provider. Health practitioner will support the patient by providing the best evidence available to inform patient about options, exploring their values and preferences in order to make the best decision for them (Edwards and Elwyn, 2009).

In 1997, Charles, Gafni and Whelan proposed a model for SDM. The model described characteristics and requirements needed to achieve a SDM process. There is number of healthcare contexts where patients face difficult, preference-sensitive decisions (O'Connor et al., 2009). The health provider and the patient become involved in the decision as they share information (professionals will offer the best evidence available and patient will share his experiences, values and feelings). Considering that SDM seeks to ensure that the patient has adequate and accurate information, decision support interventions have been developed to provide information about the options and probabilities of risks and benefits of each alternative (Elwyn et al., 2009). These interventions might help to build consensus and achieve agreement. Figure 1 summarizes the model (Charles et al., 1997).

\section{How Can the SDM Contribute to the Debate Held by the Chilean Government and the Students in Chile?}

Little has been described in Chilean literature about people's participation in SDM. A recent paper described that there is a growing interest in involving people in SDM. Some efforts includes the general consultation and public discussion of the

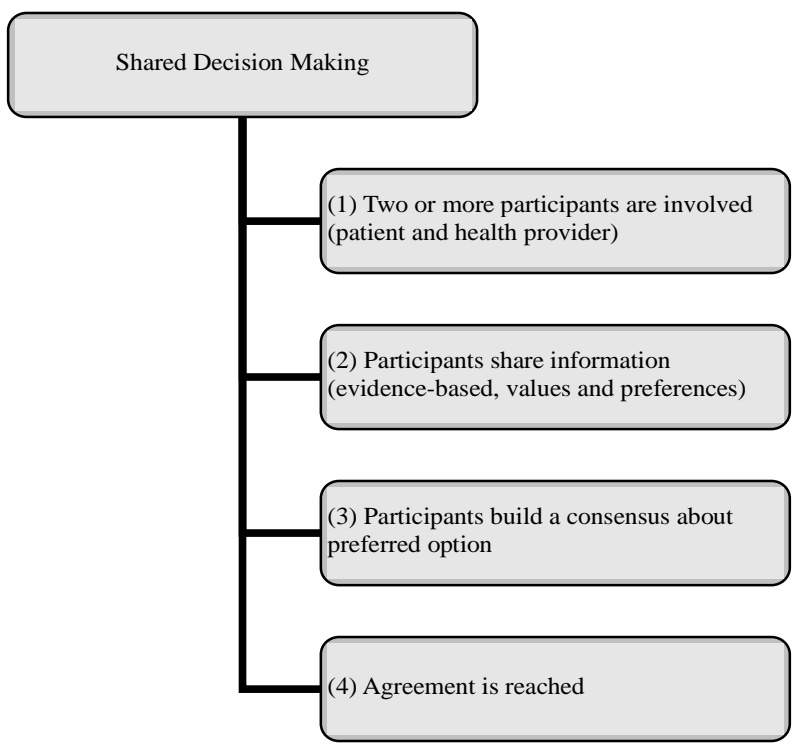

Figure 1.

The SDM in health model.

Health Reform (Bravo et al., 2011). However, it seems those efforts are restricted to health related issues and have not reach other areas of social concern.

The Overseas Development Institute stated that it is essential to incorporate different sources of knowledge to inform decision making in policy (Jones et al., 2009). Participatory knowledge, which involves people's participation through experiences and local understanding, is a key element for effective interventions (Jones et al., 2009). Moreover, the effectiveness of changes increases when those directly affected by the change feel reonsibility for the process and have a sense of ownership for what is happening (Liontos, 1994).

Shared decision making could be an effective approach to deal with the current political situation in Chile. Similar to the medical encounter-where a "medical expert" provides services to the "patient"- the current debate includes in a major scale the expert (government) and the patient (students). The young generation is claiming for a voice and for balance in power. They feel they hold political responsibility (Jones et al., 2009) and they want to be part of the decision making to improve the educational system.

We believe the student educational revolution is a great opportunity to develop a SDM process and that students and the government can benefit from the knowledge from this model. This multidimensional theoretical approach has been conceptualized from sound evidence developed in the past decades and might lead the path to success in this complex and unsolved conflict in Chile.

Students and the whole nation have identified a sensitive dilemma that is whether or not to reform the educational system. The two parties, citizens and government are willing to be involved in the decision making process. However, it seems that the "sharing information" step is not strong enough to give the sense of inclusion and value of participatory knowledge. Consequently, the consensus has not been reached, and agreement seems to be far to achieve. In 2012 students continue organizing pacific protests to demand change and participation, but little progress is perceived as communication pathways between 
parties are someone resenting the long-term debate.

\section{What Future Steps Should Be Taken to Contribute to Achieve True "Participatory" Democracy in Chile?}

As healthcare providers and researchers we believe that this is an excellent opportunity to begin changing the "passive" nature of Chilean society towards a "participatory and engaged" one. The students are the new generation, and this sense of responsibility of issues that matters to them (such as education) could help to improve other areas in which people's participation has proved to be a key element for success. Having empowered and active students today can help us to have empowered and active adults in the future. These empowered young adults may be more willing to take responsibilities on health-related issues, public economy and policy making. This is why we believe that a great attention should be given to how the students' demands are responded to.

Following the SDM in health model, we propose that some changes take place to reach agreement. First, as information has not been shared adequately, both parties might feel a sense of power imbalance. Therefore, it is important to reassure that information will be clear, evidence and practice-based and equally available for both parties. Secondly, and only once information is properly shared and agreed, then participants (that is, the students in Chile) should develop a series of recommendations on the preferred decisions to make to improve the public educational system in the country. The current situation could adopt some engaging strategies that have been used in healthrelated issues. In 2003 the Health Reform proposed the creation of steering committees (known as Council Care Network Integrators). These committees involved professionals and community participants who provided support and advice to health services and proposed community-tailored local health policies. This strategy has proven successful with over 30 committees actively operating across the country (Bravo et al., 2011).

Currently, students have already presented clear statements of what commitments they require the government to fulfill in order to reach agreement and return to usual activities, but the government has denied the ability to respond to them. Further efforts need to be made from both sides in order to identify a shared goal that can be truly achieved in the near future. Following the knowledge from SDM, this could be done by a clear establishment of a partnership between both parties. So far, Chile has shown a more "domination" orientated culture (Eisler and Corral, 2005), where repression, fear and violence have led the dialogue regarding education. Government and students should be considered equally important for the decision making process, and both are expected to contribute with solutions and alternatives to the problem. It is this sense of partnership and inclusion that could agreement will be reached. According to the SDM approach, only when a clear partnership is established and all parties involved in the decision can contribute with knowledge, values and feelings in regards to the options, the consensus can be achieved in an unbiased and democratic way.

In conclusion, the students' movement in Chile is a strategic opportunity to develop a shared decision making process in the country. The current government needs to truly understand the real importance of the opinion of those directly involved in the policy decisions that are made every day, and this educational manifestation sets the case for better development of a formal, well-informed, SDM process in Chile. This essay provides a reflection on how the SDM contribute to the debate held by the Chilean Government and the students and also on what future steps should be taken to contribute to achieve true "participatory" democracy in Chile. The debate should not only include information exchange, as the level of participation must rely on the establishment of a partnership between parties, which demonstrate all views, feelings and contributions are equally valuable and respected, and where people can freely state "what matters to them".

\section{REFERENCES}

Bravo, P., Cabieses, B., Bustamante, C., Campos, S., \& Stacey, D. (2011). Shared decision making in Chile: Supportive policies and research initiatives. Zeitschrift für evudenz, fortbildung und qualitåt im Gesundheitswesen, 105, 254-258. doi:10.1016/j.zefq.2011.04.007

Cabieses B., Tunstall H., \& Pickett K. E. (2010). Describing social determinants of health of the Chilean-born and international immigrants in Chile. Oral presentation. PILAS Conference 2010. Manchester: University of Manchester, 8.

Charles, C., Gafni, A., \& Whelan, T. (1997). Shared decision-making in the medical encounter: What does it mean? (or it takes at least two to tango). Social Science Medicine, 44, 681-692. doi:10.1016/S0277-9536(96)00221-3

Chilean Ministry of Health (2011). Objetivos sanitarios de la decada 2011-2020. URL (last checked April 2012). www.minsal.cl

Edwards, A., \& Elwyn, G. (2009). Shared decision-making in health care: Achieving evidence-based patient choice. In: A. Edwards, \& G. Elwyn (Eds.), Shared decision-making in health care: Achieving evidencebased patient choice (pp. 3-10). New York: Oxford University Press.

Eisler, R., \& Corral, T. (2005). From domination to partnership: Meeting the UN millennium goals. Convergence, 38, 75-94.

Elwyn, G. (2010). Salzburg statement on shared decision making. BMJ, 342, d1745. doi:10.1136/bmj.c5146

Elwyn, G., Edwards, A., Gwyn, R., \& Grol, R. (1999). Towards a feasible model for shared decision making: Focus group study with general practice registrars. BMJ, 319, 753-756. doi:10.1136/bmj.319.7212.753

Elwyn, G., Frosch, D., \& Rollnick, S. (2009). Dual equipoise shared decision making: Definitions for decision and behaviour support interventions. Implementation Science, 4, 75-82. doi:10.1186/1748-5908-4-75

Franklin, J. (2011). Chile's Commander Camila, the student who can shut down a city. The Guardian online. http://www.guardian.co.uk/world/2011/aug/24/chile-student-leader-c amila-vallejo

Hårter, M., van der Weijden, T., \& Elwyn, G. (2011). Policy and practice developments in the shared decision making: An intrnational perspective. Zeitschrift für evudenz, fortbildung und qualitåt im Gesundheitswesen, 105, 229-233. doi:10.1016/j.zefq.2011.04.018

Jones, N., Datta, A., \& Jones, H. (2009). Knowledge, policy and power. In: O. D. Institute (Ed.), Types of knowledge (pp. 6-8). London: Overseas Development Institute.

Kuhns, D. E., \& Chapman, P. E. (2006). How does shared decision making impact inclusion. National Forum of Special Education Journal, 17, 1-17.

Liontos, L. B. (1994). Shared decision-making. Eugene, OR: ERIC Clearinghouse on Educational Management. http://eric.uoregon.edu/publications/digests/digest087.html

Niemira, D. (2009). Ethics conflicts in rural communities: Shared decision-making. In: W. A. Nelson (Ed.), Handbook for rural health care ethics: A practical guide for professionals (pp. 142-163). New Hampshire: University Press of New England.

O’Connor, A. M., Bennett, C. L., Stacey, D., Barry, M., Col, N. F., Eden, K. B., Entwistle, V. A., et al. (2009). Decision aids for people facing health treatment or screening decisions.

http://www.mrw.interscience.wiley.com/cochrane/clsysrev/articles/C D001431/frame.html 